\title{
Loading conditions in the spine, hip and knee during different executions of back extension exercises
}

\author{
Florian Schellenberg, Nicole Schmid, Ramona Häberle, Nicole Hörterer, William R. Taylor and Silvio Lorenzetti ${ }^{*}$ (D)
}

\begin{abstract}
Background: Back extension (BE) is a strength exercise for training the dorsal trunk and hip muscles. To optimise training recommendations that avoid overloading and possible injury, the aim of this study was to determine the loading conditions and the influence of different execution forms of BE on spine, hip and knee ranges of motion (RoMs), joint moments and muscle activity.

Methods: The kinematics, kinetics and muscle activity (EMG) of two execution types ( $B E_{h}$ : dynamic hip, $B E_{s}$ : dynamic spine) and two versions (one-legged and two-legged) of BE were measured in 16 subjects. RoMs and external joint moments were calculated using an inverse dynamics approach and analysed with a linear mixed model.

Results: Although lumbar spine flexion was observed in both execution types, thoracic spine flexion predominantly occurred during $\mathrm{BE}_{s_{s}}$ whereas thoracic spine extension was observed during $\mathrm{BE}_{\mathrm{h}}$. Larger maximal back and hip moments were observed for $\mathrm{BE}_{\mathrm{h}}$ than for $\mathrm{BE}_{\mathrm{s}}$. The activity of the dorsal back and hip muscles, as observed using $\mathrm{EMG}$, was increased for one-legged executions.

Conclusion: To strengthen the hips and lower back, $\mathrm{BE}_{\mathrm{h}}$ seem to be more efficient due to the higher moments, with higher or similar RoMs in the hip and lower back. One-legged $\mathrm{BE}_{\mathrm{s}}$ seem to provide an effective training for the hamstrings and hip regions without subjecting the spine to excessive loading, possibly promoting this as an effective exercise during training and rehabilitation.
\end{abstract}

Keywords: Strength training, External joint moments, Ranges of motion, EMG, Trunk, Lower extremities, Rehabilitation

\section{Background}

Strength exercises are part of most training and rehabilitation programs. The back extension (BE) is often performed by athletes as well as low back pain patients to strengthen the dorsal trunk and hip musculature [1]. Because a majority of injuries during strength training occur due to the overloading and incorrect execution of the exercises [2], biomechanical knowledge of the loading conditions that occur during BE exercises, especially in the hip and knee joints and in the lower back, is important to provide safe and efficient recommendations for training and rehabilitation.

\footnotetext{
* Correspondence: slorenzetti@ethz.ch; sl@ethz.ch Institute for Biomechanics, ETH Zürich, HCP H 21.1, Leopold-Ruzicka-Weg 4, 8093 Zürich, Switzerland
}

Two dynamic types of BE are commonly used: the activity can be predominantly driven either by movement at the hip while the spine is stabilised $\left(\mathrm{BE}_{\mathrm{h}}\right)$ or by movement at the spine executed with a stabilised hip $\left(\mathrm{BE}_{\mathrm{s}}\right)$. In addition, one- and two-legged versions are also possible and frequently used. Historically, the execution of $\mathrm{BE}_{\mathrm{s}}$ has been based on the Sorensen test, which was developed to assess the isometric endurance of the dorsal trunk muscles [3, 4]. During this test, subjects lie on a table with their held legs horizontal to the ground and attempt to hold their unsupported upper body stable for as long as possible. In a more recent development of the exercise, instead of a horizontal table, a variable-angle Roman chair is used, which allows the legs to be placed at an angle to the horizontal of, e.g., $45^{\circ}[1,5-8]$, and thereby allows the highest loading conditions (i.e., when 
the upper body is horizontal) to act at different hip flexion angles [9]. This idea has been supported by electromyography (EMG) measurements that demonstrated changes in lumbar muscle activity resulting from different starting postures and the associated changes in muscle lengths [10]. In addition, higher endurance of the lumbar dorsal trunk muscles has been observed when $\mathrm{BE}$ was performed on a variable-angle Roman chair compared to the horizontal Sorensen set-up [5]. These authors assumed that the contribution of the passive structures, mainly the thoraco-lumbar fascia, was greater due to the increased stretch of the hip extensors in the variable-angle Roman chair set-up and that less lumbar muscle effort was thus required to support the mass of the upper body.

Many studies have investigated the muscle recruitment of trunk and hip muscles in different forms of BE exercises. Direct comparisons between these studies should be considered with caution because the test protocols and analyses were different. Lumbar and thoracic trunk muscles were highly activated during $\mathrm{BE}$ without additional loading (39-56 and 43\% maximum voluntary contraction (MVC) on a $40^{\circ}$ Roman chair) and similar between different execution forms. Gluteal and hamstring activities can be slightly increased using a more horizontal BE execution ( $40^{\circ}$ Roman chair: $15-23 \%$, $12-$ $16 \%$ MVC, respectively; horizontal position: $22-23$ and $16-24 \%$ MVC, respectively) $[1,11]$.

Changing the kinematic parameters during $\mathrm{BE}$ lead to different activation levels and different spine postures (e.g., $+18 \%$ activation level for lumbar extensors with an accentuated lumbar lordosis of $+25 \%$ by performing $\mathrm{BE}$ with an internal rotated hip) [8]. Therefore, different loading conditions act on the spine with different execution forms and lead to different risks of injury because disk deformation and ligament and spinal loading can be reduced if $\mathrm{BE}$ exercises are performed with neutral lordosis [11].

Distinct recommendations are missing in the literature and controversially discussed, such as for the specific strengthening of the lumbar trunk muscles relative to hip extensors. Whereas Da Silva and co-workers [1] stated that a $40^{\circ}$ Roman chair reduced the activity of the biceps femoris but did not alter the activity of the lumbar back extensors compared to a horizontal position, Mayer and co-workers [9] found that the lumbar back extensors were more active in a more horizontal position. Furthermore, Larivière and co-workers [7] stated that the $40^{\circ}$ condition was not well suited to specifically fatigue the dorsal back muscles relative to the dorsal hip muscles. Moreover, increased external load or several sets of exercises could increase the muscle activity of the hip extensors to a higher degree than that of the lumbar back extensors and therefore more specifically train the dorsal hip muscles [12]. In contrast, with an external load of $60 \%$ of $1 \mathrm{RM}$, De Ridder and co-workers [13] stated that the gluteal muscles played a smaller role compared to the lumbar muscles. Regarding the breathing pattern during strength training, the National Strength and Conditioning Association recommends to instruct athletes to exhale through the sticking point and to inhale during the less stressful phase of the repetition [14].

A detailed biomechanical analysis of the movement, loading patterns and muscle activities of the BE exercise including trunk, hip and knee joints, is missing. However, as stated above, to avoid injuries and derive training recommendations, knowledge of the loading conditions is fundamental.

Therefore, the aim of this study was to determine the influence of different execution forms of BE exercises on the spine, hip and knee ranges of motion (RoMs) and the corresponding external joint moments as well as muscle activities. The different execution forms include single or double legged execution, performed either using an isometric hip and a dynamic spine or using a dynamic hip and an isometric spine.

\section{Methods \\ Participants}

Sixteen subjects (8male, 8female, age $26.3 \pm 4.2$ years, body mass $71.9 \pm 15.1 \mathrm{~kg}$, height $1.76 \pm 0.09 \mathrm{~m}$ ) were evaluated and provided written informed consent to participate in this study. They were required to have personal experience in strength training, be physically active at least three hours per week and have neither past surgery on back, hip or knee nor any current injuries or illnesses. All subjects were instructed to wear normal sports shoes and shorts, and female subjects additionally wore a bikini top. The study was approved by the ethics committee of ETH Zurich, Switzerland (EK 2014-N-31).

\section{Data acquisition}

To analyse the kinematic motion of the body, 21 cameras (MX40 and MX160) of an opto-electronic motion system (Vicon, Oxford Metrics Group, Oxford, UK) operating at a sampling frequency of $100 \mathrm{~Hz}$ were used. 77 reflective markers were placed onto the subjects according to the method described by List and co-workers [15]. The markers were attached to the upper and lower extremities, the pelvis, and the trunk using double-sided, skin-friendly tape. The markers on the feet and spine had a diameter of $9 \mathrm{~mm}$, whereas the markers on the other segments had a diameter of $14 \mathrm{~mm}$. To functionally determine the joint centres of the ankle, knee and hip joints, the subjects performed standardised basic motion tasks [15].

The ground reaction forces were measured using two $40 \times 60 \mathrm{~cm}^{2}$ force plates (type 9281B Kistler Instrumente 
AG, Winterthur, Switzerland) operating at $2 \mathrm{kHz}$. The specially constructed $\mathrm{BE}$ bench consisting of two mechanically decoupled parts was mounted onto these force plates (Fig. 1). The frontal part was adjusted in height such that the subject's hip joint centre was just above the edge of the bench. Moreover, the force plates were specifically calibrated to correct the centre of pressure [16].

To record muscle activities, surface EMG was used. 16 EMG sensors (Trigno "wi Wireless EMG System, Delsys, USA) operating at a frequency of $2 \mathrm{kHz}$ were placed bilaterally onto the following muscle bellies [17]: M. gluteus maximus (GlutMax), M. gluteus medius (GlutMed), lateral hamstrings (HamLat), medial hamstrings (HamMed), lumbar part of M. erector spinae (ErecLum), thoracic part of $M$. erector spinae (ErecThor), $M$. rectus abdominis (Abdo) and M. obliquus externus abdominis (Obli). After a five-minute general warm-up, the subjects performed standardised MVC tasks [18]. Directly thereafter, the subjects received standardised instructions (Table 1) and performed randomized the following types of $\mathrm{BE}$ :

- $\mathrm{BE}_{\mathrm{h}}$ : Dynamic flexion and extension of the hip while the spine is stabilised in its neutral position.

- $\mathrm{BE}_{\mathrm{s}}$ : Dynamic flexion and extension of the spine (vertebrae by vertebrae) while the hip is stabilised in its neutral position.

These two types were each executed two-legged (2L) and one-legged (1L, left and right). To allow proper averaging, eight repetitions of each execution form were performed, for a total of 48 repetitions per subject. Between each execution form, there was a break of at least 90 seconds. Because there was no additional loading,

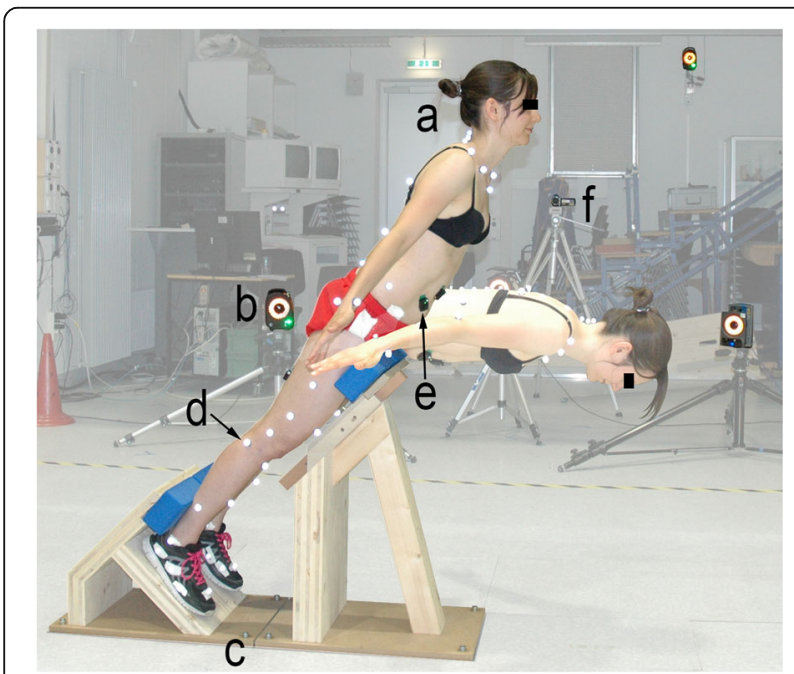

Fig. 1 Measurement Setup: Back Extension (BE) exercises on a 45 BE bench: a: subject, b: opto-electronic motion cameras, c: two decoupled force plates, d: reflective markers, e: EMG sensors, f: video camera
Table 1 The following instructions were given to the subject to ensure correct execution of the exercises

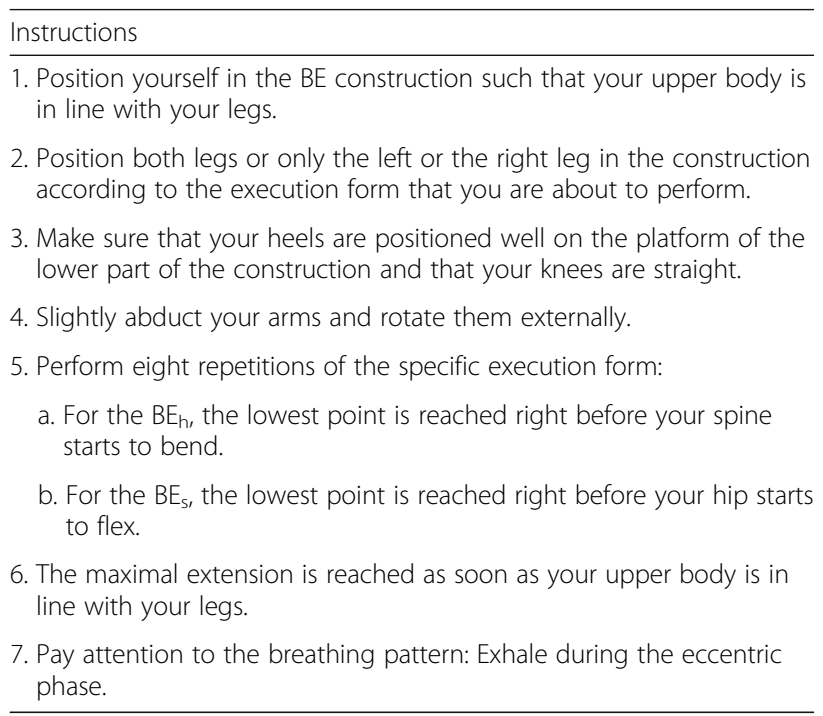

this test protocol was expected to be in a submaximal range for $\mathrm{BE}$ for all participants.

\section{Data processing \& analysis}

The kinetic and kinematic data were reconstructed in Vicon Nexus (version 1.8, Oxford Metrics Group, UK), and any further calculations were conducted with Matlab (version 8.3, The MathWorks Inc., Natick, MA, USA).

The joint centres of ankle, knee and hip were determined functionally using the data from the basic motion tasks [15], whereas the joint centre of L4/L5 was defined anatomically based on anthropometric data [19]. The highest value (peak) reached by the middle point between the shoulder markers and its corresponding time point defined the starting and ending point of each repetition. If there was more than one peak between two repetitions, the first peak was taken as the ending point of the former repetition, and the last peak was taken as the starting point of the following repetition. For the first and last repetitions to be included, the height of the shoulder markers had to lie within $10 \%$ of the following or the previous repetition, respectively. The repetitions were time-normalised according to the defined starting and ending points.

The joint moments in the knee, hip and back (L4/L5) were calculated using a quasistatic inverse dynamic approach [20] that considered the joint centres, the ground reaction forces [21] and the gender-specific different segment masses [22]. The resulting joint moments were normalised to the subject's body mass. Joint angles were based on a least squares fit of redundant skin marker clouds [23] and a helical axis approach [24], and the orthogonal anatomically defined joint coordinate systems [15] were defined. The RoMs 
for the hip, knee and different parts of the back were calculated, as were the lumbar and thoracic spine curvature and range of curvature [15].

The means and standard deviations over all 8 repetitions of a particular execution form and all subjects were calculated for the RoMs $\left[^{\circ}\right]$ of the middle to upper back $\left(\operatorname{RoM}_{\text {mub }}\right)$, lower to middle back $\left(\operatorname{RoM}_{\mathrm{lmb}}\right)$, pelvis to lower back $\left(\operatorname{RoM}_{\mathrm{plb}}\right)$, hip $\left(\operatorname{RoM}_{\mathrm{h}}\right)$ and knee $\left(\operatorname{RoM}_{\mathrm{k}}\right)$. For the lumbar and thoracic curvature $[1 / \mathrm{m}]$, the starting $\left(\mathrm{C}_{\mathrm{l}, \mathrm{s}}, \mathrm{C}_{\mathrm{t}, \mathrm{s}}\right)$ and reversal points $\left(\mathrm{C}_{\mathrm{l}, \mathrm{rp}}, \mathrm{C}_{\mathrm{t}, \mathrm{rp}}\right)$ of the movement and the maximal joint moments $[\mathrm{Nm} / \mathrm{kg}]$ of back at $\mathrm{L} 4 / \mathrm{L} 5\left(\mathrm{M}_{\mathrm{b}, \max }\right)$, hip $\left(\mathrm{M}_{\mathrm{h}, \max }\right)$ and knee $\left(\mathrm{M}_{\mathrm{k}, \max }\right)$ were calculated. Positive values corresponded to flexion angles, and positive moments corresponded to external flexion moments.

EMG data processing involved zero compensation, rectification, a third-order Butterworth $(10-500 \mathrm{~Hz})$ and a moving average filter (49 frames) [adapted from: [25]. The following parameters were chosen as the threshold: (20\% of the maximal peak), threshold for the on/offpattern (10\% MVC), minimal sub period duration "on" (25 ms) and minimal sub period duration "off" (13 ms). Muscles reaching values higher than three times the MVC for a specific trial were excluded from that trial. The means of the processed EMG signals over all cycles of each subject were then calculated separately for the concentric and eccentric phase of each muscle (mean curve parameters). Furthermore, a Fast-Fourier-Transformation (FFT) was performed to calculate the median frequency both for each repetition and for the whole trial. To evaluate fatigue during each trial and during the whole session, the mean frequency of the first repetition or trial was set to zero, and the deviation of the median frequency of each repetition or trial from this initial value was calculated.

\section{Statistical analysis}

All statistical analyses were conducted using IBM SPSS Statistics (version 22, SPSS AG, Zurich, Switzerland). The normal distribution was visually evaluated using Q-QPlots and tested with Kolmogorov-Smirnov-Tests for each parameter. A linear mixed model (significance: $\mathrm{p}<0.05$ ) was used for statistical analysis. Significant differences of all parameters between $\mathrm{BE}_{\mathrm{h}}$ and $\mathrm{BE}_{\mathrm{s}}$ and among $1 \mathrm{~L}$ and $2 \mathrm{~L}$ within $\mathrm{BE}_{\mathrm{h}}$ and $\mathrm{BE}_{\mathrm{s}}$ were examined and adjusted using Bonferroni correction within each statistical test.

\section{Results}

In general, no differences between left and right $1 \mathrm{~L}$ were found. Therefore, they were analysed together. Additionally, the FFT analysis did not show any fatigue between the different trials, which indicated that the breaks were sufficiently long to fully recover between the different execution types. The kinematic and kinetic results for back, hip and knee and the muscular activities are presented below.

\section{Back}

\section{Kinematics}

For all RoMs (back, hip and knee), significant differences between $\mathrm{BE}_{\mathrm{h}}$ and $\mathrm{BE}_{\mathrm{s}}$ were found. Whereas higher RoMs for $\mathrm{BE}_{\mathrm{s}}$ acted in the middle and upper back, higher values were found in the lower back during $\mathrm{BE}_{\mathrm{h}}$ compared to $\mathrm{BE}_{\mathrm{s}}$. (Tables 2 and 3).

The RoM of $C_{l}$ was comparable for $\mathrm{BE}_{\mathrm{h}}$ and $\mathrm{BE}_{\mathrm{s}}$ (Fig. 2c and Tables 2). The curvature in the thoracic region $\left(C_{t}\right)$ proceeded differently between $B_{h}$ and $B E_{s}$ during a cycle, which led to significant different starting and reversal points of $\mathrm{C}_{t}$ (Fig. 2d, Tables 2 and 3). Moreover, for $\mathrm{BE}_{\mathrm{s}}, \mathrm{C}_{\mathrm{t}, \mathrm{s}}$ was larger for $2 \mathrm{~L}$ compared to $1 \mathrm{~L}$.

\section{Kinetics}

$M_{b, \max }$ was $0.1 \mathrm{Nm} / \mathrm{kg}$ greater for $\mathrm{BE}_{\mathrm{h}}$ than for $\mathrm{BE}_{\mathrm{s}}$ for all versions and occurred at the reversal point (Fig. 2c, Tables 2 and 3 ).

\section{Hip \\ Kinematics}

$\mathrm{RoM}_{h}$ was twice as high for $B E_{h}$ than for $\mathrm{BE}_{\mathrm{s}}$ for all versions. Additionally, a shifted starting point for $1 \mathrm{~L}$ executions could be identified, which led to a smaller $\mathrm{RoM}_{\mathrm{h}}$ for $1 \mathrm{~L}$ compared to $2 \mathrm{~L}$ during $\mathrm{BE}_{\mathrm{h}}$ (Fig. $2 \mathrm{~b}$; Tables 2 and 3).

\section{Kinetics}

For all versions, $M_{h, \max }$ was approximately $0.2 \mathrm{Nm} / \mathrm{kg}$ higher for $\mathrm{BE}_{\mathrm{h}}$ than for $\mathrm{BE}_{\mathrm{s}}$; for both types, it was approximately $0.3 \mathrm{Nm} / \mathrm{kg}$ higher for $1 \mathrm{~L}$ compared to $2 \mathrm{~L}$. $\mathrm{M}_{\mathrm{h} \text {,max }}$ occurred at the reversal point for all execution forms (Fig. 2b, Tables 2 and 3).

\section{Knee}

\section{Kinematics}

The participants fully extended their knees during $\mathrm{BE}_{\mathrm{h}}$, whereas during $\mathrm{BE}_{\mathrm{s}}$, they kept their knees in a slightly bent position. This difference techniques resulted in a greater $\operatorname{RoM}_{\mathrm{k}}$ for $\mathrm{BE}_{\mathrm{h}}$. The $1 \mathrm{~L}$ executions already started with more extended legs compared to $2 \mathrm{~L}$, which caused a higher $\operatorname{RoM}_{\mathrm{k}}$ for $2 \mathrm{~L}$ executions during $\mathrm{BE}_{\mathrm{h}}$ (Fig. 2a, Tables 2 and 3).

\section{Kinetics}

$\mathrm{M}_{\mathrm{k}, \max }$ occurred at the reversal point and was more than $0.1 \mathrm{Nm} / \mathrm{kg}$ higher for $\mathrm{BE}_{\mathrm{h}}$ than $\mathrm{BE}_{\mathrm{s}}$ for all versions and higher for $1 \mathrm{~L}$ than for $2 \mathrm{~L}$ for both types (Fig. 2a, Tables 2 and 3). 
Table 2 Ranges of motions (RoMs) and maximal external joint moments. RoM [ ${ }^{\circ}$ ] of middle to upper back (RoM mub), lower to middle back $\left(\right.$ RoM $\left.M_{\text {mb }}\right)$, pelvis to lower back $\left(\operatorname{RoM}_{\mathrm{plb}}\right)$, hip $\left(\operatorname{RoM}_{h}\right)$ and knee $\left(\operatorname{RoM}_{\mathrm{k}}\right)$, lumbar and thoracic curvature $[1 / \mathrm{m}]$ at starting $\left(C_{1, s,} C_{t, s}\right)$ and reversal point $\left(C_{1, r p}, C_{t, r p}\right)$ as well as maximal joint moments $[N m / k g]$ of back $\left(M_{b, \max }\right)$, hip $\left(M_{h, \text { max }}\right)$ and knee $\left(M_{k, \text { max }}\right)$ in the sagittal plane for the different types $\left(\mathrm{BE}_{h}, \mathrm{BE} \mathrm{E}_{\mathrm{s}}\right)$ and versions $(1 \mathrm{~L}, 2 \mathrm{~L})$ of $\mathrm{BE}$ were given

\begin{tabular}{|c|c|c|c|c|c|c|c|c|c|c|c|c|c|}
\hline & & $\begin{array}{l}\text { RoM mub } \\
{\left[^{\circ}\right]}\end{array}$ & $\begin{array}{l}\text { RoM } M_{\operatorname{lmb}} \\
{\left[^{\circ}\right]}\end{array}$ & $\begin{array}{l}\text { RoM } M_{\text {plb }} \\
{\left[^{\circ}\right]}\end{array}$ & $\begin{array}{l}\text { RoMh } \\
{\left[^{\circ}\right]} \\
\end{array}$ & $\begin{array}{l}\text { RoMk } \\
{\left[^{\circ}\right]} \\
\end{array}$ & $\begin{array}{l}\mathrm{C}_{1,5} \\
{[1 / \mathrm{m}]}\end{array}$ & $\begin{array}{l}C_{1, r p} \\
{[1 / m]}\end{array}$ & $\begin{array}{l}C_{t, s} \\
{[1 / m]}\end{array}$ & $\begin{array}{l}C_{t, r p} \\
{[1 / m]}\end{array}$ & $\begin{array}{l}M_{b, \max } \\
{[\mathrm{Nm} / \mathrm{kg}]}\end{array}$ & $\begin{array}{l}M_{h, \max } \\
{[\mathrm{Nm} / \mathrm{kg}]}\end{array}$ & $\begin{array}{l}M_{k, \max } \\
{[\mathrm{Nm} / \mathrm{kg}]}\end{array}$ \\
\hline \multirow[t]{2}{*}{$B E_{h}$} & $1 \mathrm{~L}$ & $8.9 \pm 3.7$ & $14.8 \pm 6.0$ & $16.6 \pm 5.0$ & $29.6 \pm 7.4$ & $5.3 \pm 2.9$ & $6 \pm 2.1$ & $-0.1 \pm 1.1$ & $2.4 \pm 0.7$ & $1.8 \pm 0.8$ & \pm 0.2 & $1.1 \pm 0.2$ & $-0.8 \pm 0.2$ \\
\hline & $2 \mathrm{~L}$ & $10 \pm 4.5$ & $12.5 \pm 5.1$ & $17.4 \pm 5.0$ & $36.3 \pm 7.9$ & $4 \pm 3.6$ & $.2 \pm 2.0$ & $0 \pm 1.2$ & $2.6 \pm 0.6$ & $1.8 \pm 0.8$ & $1.1 \pm 0.2$ & $0.8 \pm 0.1$ & $-0.5 \pm 0.1$ \\
\hline \multirow[t]{2}{*}{$\mathrm{BE}_{s}$} & $1 \mathrm{~L}$ & $16.6 \pm 4.2$ & $36 \pm 9.3$ & $11.7 \pm 7.3$ & $14.1 \pm 9.9$ & $2.9 \pm 2.3$ & $5.7 \pm 2.2$ & $0 \pm 1.9$ & $2 \pm 0.7$ & $3.3 \pm 0.6$ & $0.9 \pm 0.2$ & $0.9 \pm 0.2$ & $-0.6 \pm 0.2$ \\
\hline & $2 \mathrm{~L}$ & $14.7 \pm 3.2$ & $35.9 \pm 10.1$ & $13.8 \pm 8.6$ & $15.5 \pm 11.7$ & $3.5 \pm 3.4$ & $5.4 \pm 2.1$ & $-0.6 \pm 1.5$ & $2.2 \pm 0.7$ & $3.3 \pm 0.6$ & $1 \pm 0.2$ & $0.7 \pm 0.1$ & $-0.4 \pm 0.1$ \\
\hline
\end{tabular}

\section{Muscular activity \\ Eccentric phase}

GlutMax and GlutMed showed higher activities for the trained leg of $1 \mathrm{~L}$ executions compared to $2 \mathrm{~L}$ executions for both types of $\mathrm{BE}$. HamLat was more active for $\mathrm{BE}_{\mathrm{s}}$ than $\mathrm{BE}_{\mathrm{h}}$ for $2 \mathrm{~L}$. HamMed for $\mathrm{BE}_{\mathrm{h}}$ and ErecLum For $\mathrm{BE}_{\mathrm{s}}$ were more active for $1 \mathrm{~L}$ than $2 \mathrm{~L}$, whereas ErecThor showed a higher activity for $\mathrm{BE}_{\mathrm{h}}$ compared to $\mathrm{BE}_{\mathrm{s}}$. Abdo and Obli were more active for $\mathrm{BE}_{\mathrm{s}}$ than $\mathrm{BE}_{\mathrm{h}}$, however, the activity level for these muscles was very low (Tables 4 and 5).

\section{Concentric phase}

Similarly, GlutMax, GlutMed and ErecLum showed higher activities for the trained leg of $1 \mathrm{~L}$ compared to 2L. HamLat was more active in $\mathrm{BE}_{\mathrm{h}}$ during $1 \mathrm{~L}$ execution, whereas ErecThor showed a higher activity for $\mathrm{BE}_{\mathrm{h}}$ compared to $\mathrm{BE}_{\mathrm{s}}$ for all types (Tables 4 and 5).

\section{Discussion}

The aim of this study was to study the influence of different $\mathrm{BE}$ execution forms on the spine, hip and knee RoMs, external joint moments and on the muscle activity. In total, 16 subjects performing six different versions of BE were measured and analysed.

\section{Back}

\section{Kinematics}

Due to the different exercise specifications, higher RoMmub, RoM $M_{\text {lmb }}$ and $C_{t, r p}$ and smaller RoM $M_{\text {plb }}$ were expected for $\mathrm{BE}_{\mathrm{s}}$ compared to $\mathrm{BE}_{\mathrm{h}}$ and could be analysed (Tables 2 and 3). It is remarkable that a similar lumbar spine flexion was found for $\mathrm{BE}_{\mathrm{h}}$ compared to $\mathrm{BE}_{\mathrm{s}}$. However, whereas a thoracic spine flexion was analysed during $B E_{s}$, a spine extension was observed during $B_{h}$ from the starting to the reversal point (Fig. 2c and d). This difference resulted in an opposed movement for the dorsal spine muscles in $\mathrm{BE}_{\mathrm{h}}$. This opposed movement in the spine during the eccentric part of $\mathrm{BE}_{\mathrm{h}}$ might affect the dorsal back muscles. ErecLum becomes stretched and experiences an eccentric force, whereas ErecThor contracts in a concentric manner.

The RoMs in the lumbar and thoracic spine of nonfatigued $\mathrm{BE}$ reported by Larivière and co-workers [7] were within the values of $\mathrm{BE}_{\mathrm{h}}$ and $\mathrm{BE}_{\mathrm{s}}$ of this study. This finding supports the assumption based on the FFT analysis of the EMG data that the BE in the present study were performed in a non-fatigued state. With fatigue, Larivière and co-workers [7] observed RoMs in the lumbar spine that were closer to those of this study's $B_{h}$, whereas the values of the RoMs in the thoracic spine were closer to those of the $\mathrm{BE}_{\mathrm{s}}$ (Table 2). Although the participants tried to start in the exact same position for all execution forms, the significant differences in $\mathrm{C}_{\mathrm{t}, \mathrm{s}}$, especially between $B E_{h}$ and $B E_{s}$, indicated that this was not entirely the case (Tables 2 and 3 ). Although $\mathrm{BE}_{\mathrm{s}}$ involved an isolated spine flexion and $\mathrm{BE}_{\mathrm{h}}$ a stabilised spine, the RoM in $C_{l}$ seemed to be comparable between $\mathrm{BE}_{\mathrm{h}}$ and $\mathrm{BE}_{\mathrm{s}}$, which indicates that it was not possible to completely isolate one movement.

\section{Kinetics}

$\mathrm{BE}_{\mathrm{h}}$ resulted in a slightly higher $\mathrm{M}_{\mathrm{b}, \max }$ (Fig. 2c, Tables 2 and 3). A higher moment in the back is assumed with a greater exerted strain on the lumbar back muscles, which probably led to a larger training effect on those specific

Table 3 The $p$-values for differences in the mean range of motion, curvature and maximal joint moments in the sagittal plane within and between types and versions

\begin{tabular}{|c|c|c|c|c|c|c|c|c|c|c|c|c|}
\hline & RoM $M_{\text {mub }}$ & $\mathrm{RoM}_{\mathrm{Imb}}$ & RoM $_{\mathrm{plb}}$ & RoM $_{h}$ & $\mathrm{RoM}_{\mathrm{k}}$ & $C_{1,5}$ & $C_{l, r p}$ & $C_{t, s}$ & $C_{t, r p}$ & $M_{b, \text { max }}$ & $M_{h, \text { max }}$ & $M_{k, \text { max }}$ \\
\hline $\mathrm{BE}_{h}: 1 \mathrm{~L} \leftrightarrow 2 \mathrm{~L}$ & 0.201 & 0.126 & 0.574 & 0.001 & 0.000 & 0.026 & 0.907 & 0.054 & 0.442 & 0.651 & 0.000 & 0.000 \\
\hline $\mathrm{BE}_{\mathrm{s}}: 1 \mathrm{~L} \leftrightarrow 2 \mathrm{~L}$ & 0.036 & 0.942 & 0.141 & 0.452 & 0.153 & 0.114 & 0.057 & 0.001 & 0.717 & 0.343 & 0.000 & 0.000 \\
\hline $1 \mathrm{~L}: \mathrm{BE}_{\mathrm{h}} \leftrightarrow \mathrm{BE}_{\mathrm{s}}$ & 0.000 & 0.000 & 0.000 & 0.000 & 0.000 & 0.733 & 0.693 & 0.000 & 0.000 & 0.000 & 0.000 & 0.000 \\
\hline $2 \mathrm{~L}: \mathrm{BE}_{\mathrm{h}} \leftrightarrow \mathrm{BE}_{\mathrm{s}}$ & 0.000 & 0.000 & 0.033 & 0.000 & 0.000 & 0.413 & 0.139 & 0.000 & 0.000 & 0.000 & 0.000 & 0.0 \\
\hline
\end{tabular}



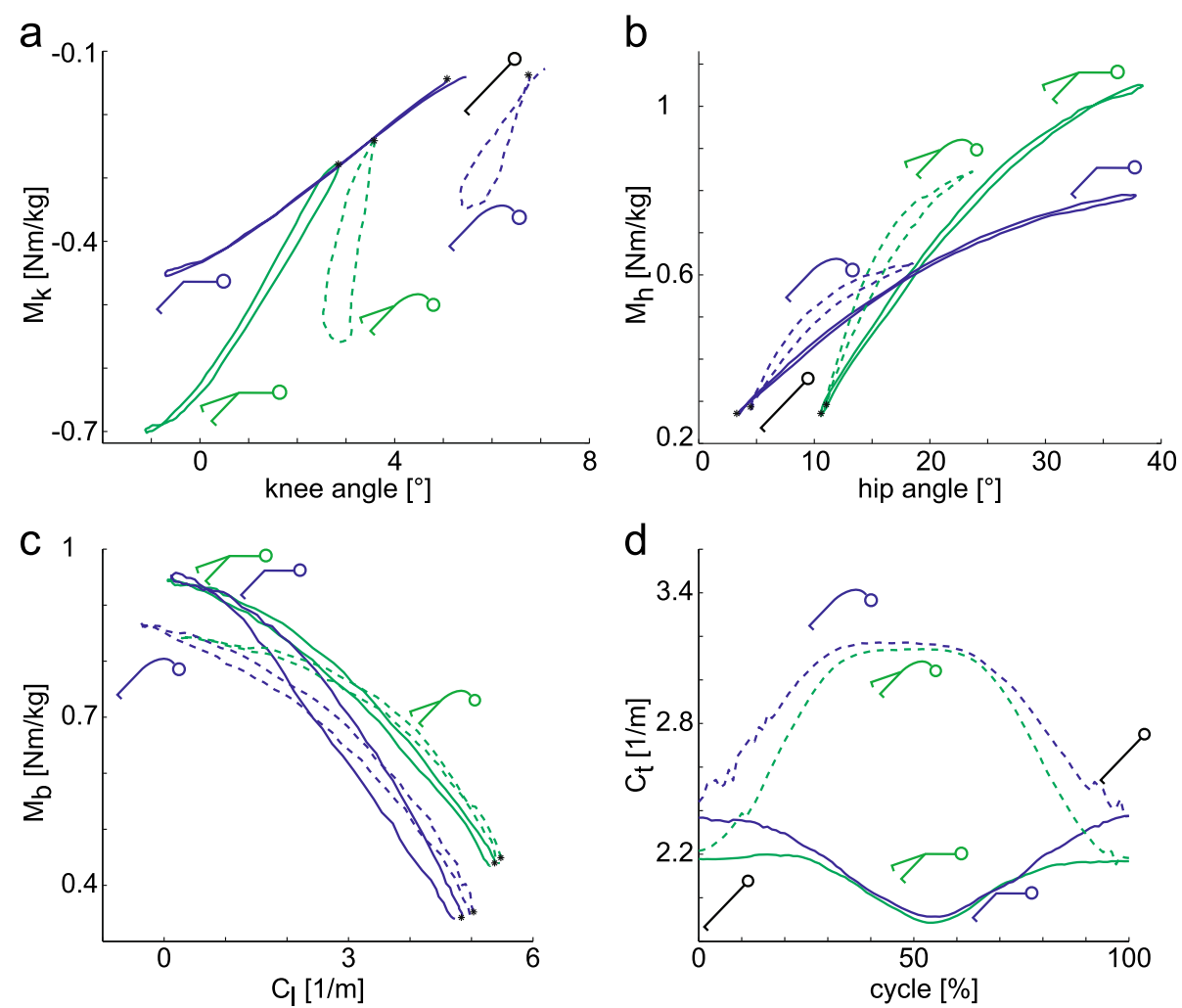

Fig. 2 Loading conditions: Moments (positive for external flexion moment) as a function of joint angle averaged over all repetitions and all subject plots are plotted for all $\mathrm{BE}$ exercise types (solid: $\mathrm{BE}_{\mathrm{h}}$, dashed: $\mathrm{BE}_{s}$; blue: $2 \mathrm{~L}$, green: $1 \mathrm{~L}^{\text {; }}$ : starting point) (a): Normalised knee moment in the sagittal plane $[\mathrm{Nm} / \mathrm{kg}]$ as a function of the corresponding knee flexion angle [ $\left.{ }^{\circ}\right]$. b: Normalised hip moment in the sagittal plane [Nm/kg] as a function of the corresponding hip flexion angle [ $\left.{ }^{\circ}\right]$. c: Normalised back moment at the level L4/L5 in the sagittal plane [Nm/kg] as a function of the corresponding lumbar curvature $[1 / \mathrm{m}]$. d: Normalised thoracic curvature in the sagittal plane $[1 / \mathrm{m}]$ for a cycle $[\%]$

muscles. This difference could be explained by a bigger lever arm of the segmental mass of the upper body in $\mathrm{BE}_{\mathrm{h}}$. For comparison, the back moments estimated for L5/S1 by Plamondon and co-workers [26] were normalised with a mean body weight (BW, $1.42 \mathrm{Nm} / \mathrm{kg}$ ). The smaller values for L4/L5 (0.94-1.05 Nm/kg) found in this study can be argued as followed. First, a less horizontal leg position causes a smaller external torque [6] and second, a smaller lever arm due to L4/L5 being more cranial compared to L5/S1 is presented. Furthermore, Plamondon and co-workers [26] described that the maximal back moment occurred at or near a horizontal trunk position, which agrees with this study's $M_{b, \max }$ occurring at the reversal point along with the smallest $\mathrm{C}_{\mathrm{l}}$ (Fig. 2c).

Comparing found back moments to other back strength exercises, such as deadlifts and goodmornings,

Table 4 Mean curve parameters of M. gluteus maximus (GlutMax), M. gluteus medius (GlutMed), lateral hamstrings (HamLat), medial hamstrings (HamMed), lumbar part of M. erector spinae (ErecLum), thoracic part of M. erector spinae (ErecThor), M. rectus abdominis (Abdo) and M. obliquus abdominis (Obli) for the eccentric and concentric phase of BE

\begin{tabular}{|c|c|c|c|c|c|c|c|c|c|c|}
\hline & & & $\begin{array}{l}\text { GlutMax } \\
\text { [\% MVC] }\end{array}$ & $\begin{array}{l}\text { GlutMed } \\
{[\% \text { MVC] }}\end{array}$ & $\begin{array}{l}\text { HamLat } \\
{[\% \text { MVC] }}\end{array}$ & $\begin{array}{l}\text { HamMed } \\
{[\% \text { MVC] }}\end{array}$ & $\begin{array}{l}\text { ErecLum } \\
\text { [\% MVC] }\end{array}$ & $\begin{array}{l}\text { ErecThor } \\
\text { [\% MVC] }\end{array}$ & $\begin{array}{l}\text { Abdo } \\
{[\% \text { MVC] }}\end{array}$ & $\begin{array}{l}\text { Obli } \\
{[\% \text { MVC] }}\end{array}$ \\
\hline \multirow[t]{4}{*}{ Eccentric } & $\mathrm{BE}_{\mathrm{h}}$ & $1 \mathrm{~L}$ & $17.4 \pm 9.9$ & $10.1 \pm 5.2$ & $11.9 \pm 5.3$ & $12.8 \pm 9.7$ & $13.6 \pm 4.7$ & $9.3 \pm 5.5$ & $2.5 \pm 4$ & $3.7 \pm 4.4$ \\
\hline & & $2 \mathrm{~L}$ & $12.7 \pm 7.0$ & $7.2 \pm 4.3$ & $10.5 \pm 5.4$ & $9.6 \pm 7.5$ & $12.3 \pm 4.6$ & $9.8 \pm 7.0$ & $2 \pm 2.2$ & $3.8 \pm 4.2$ \\
\hline & $\mathrm{BE}_{5}$ & $1 \mathrm{~L}$ & $17.9 \pm 11.0$ & $11.6 \pm 6.0$ & $13.8 \pm 6.2$ & $14.1 \pm 11.2$ & $13.7 \pm 6.0$ & $5.6 \pm 4.8$ & $3.2 \pm 3.4$ & $5.2 \pm 5.5$ \\
\hline & & $2 \mathrm{~L}$ & $13.5 \pm 7.6$ & $8.2 \pm 4.1$ & $14.4 \pm 6.5$ & $12.2 \pm 8.8$ & $11.8 \pm 6.2$ & $4.5 \pm 2.4$ & $3.4 \pm 3.3$ & $5.1 \pm 5.7$ \\
\hline \multirow[t]{4}{*}{ Concentric } & $\mathrm{BE}_{\mathrm{h}}$ & $1 \mathrm{~L}$ & $22.7 \pm 12.7$ & $13.5 \pm 6.9$ & $16.1 \pm 7.1$ & $16.4 \pm 11.6$ & $22.8 \pm 8.2$ & $9.7 \pm 6.0$ & $2.7 \pm 3.9$ & $4.6 \pm 5.3$ \\
\hline & & $2 \mathrm{~L}$ & $16.5 \pm 8.5$ & $9.3 \pm 6.0$ & $16 \pm 7.0$ & $13.3 \pm 10.0$ & $18.9 \pm 7.6$ & $9.7 \pm 7.7$ & $2.1 \pm 2.3$ & $4.3 \pm 4.6$ \\
\hline & $\mathrm{BE}_{\mathrm{s}}$ & $1 \mathrm{~L}$ & $20 \pm 12.1$ & $13 \pm 7.8$ & $13.8 \pm 6.8$ & $13.6 \pm 9.7$ & $21.1 \pm 9.4$ & $7.6 \pm 6.1$ & $2.8 \pm 3.3$ & $5.1 \pm 4.8$ \\
\hline & & $2 \mathrm{~L}$ & $15 \pm 8.6$ & $8.9 \pm 5.6$ & $14.4 \pm 6.5$ & $12 \pm 8.3$ & $17.6 \pm 7.8$ & $6.4 \pm 4.6$ & $2.9 \pm 3.3$ & $4.7 \pm 4.9$ \\
\hline
\end{tabular}


Table 5 The $p$-values for muscle activity within and between types and versions

\begin{tabular}{|c|c|c|c|c|c|c|c|c|c|}
\hline & & GlutMax & GlutMed & HamLat & HamMed & ErecLum & ErecThor & Abdo & Obli \\
\hline \multirow[t]{4}{*}{ Eccentric } & $\mathrm{BE}_{\mathrm{h}}: 1 \mathrm{~L} \leftrightarrow 2 \mathrm{~L}$ & 0.002 & 0.001 & 0.184 & 0.045 & 0.153 & 0.798 & 0.076 & 0.978 \\
\hline & $\mathrm{BE}_{\mathrm{s}}: 1 \mathrm{~L} \leftrightarrow 2 \mathrm{~L}$ & 0.004 & 0.000 & 0.504 & 0.232 & 0.006 & 0.193 & 0.493 & 0.829 \\
\hline & $1 \mathrm{~L}: \mathrm{BE}_{\mathrm{h}} \leftrightarrow \mathrm{BE}_{\mathrm{s}}$ & 0.763 & 0.098 & 0.082 & 0.389 & 0.451 & 0.000 & 0.045 & 0.039 \\
\hline & $2 \mathrm{~L}: \mathrm{BE}_{\mathrm{h}} \leftrightarrow \mathrm{BE}_{\mathrm{s}}$ & 0.579 & 0.231 & 0.000 & 0.093 & 0.538 & 0.000 & 0.000 & 0.066 \\
\hline \multirow[t]{4}{*}{ Concentric } & $\mathrm{BE}_{\mathrm{h}}: 1 \mathrm{~L} \leftrightarrow 2 \mathrm{~L}$ & 0.001 & 0.000 & 0.919 & 0.068 & 0.002 & 0.435 & 0.044 & 0.629 \\
\hline & $\mathrm{BE}_{\mathrm{s}}: 1 \mathrm{~L} \leftrightarrow 2 \mathrm{~L}$ & 0.006 & 0.000 & 0.593 & 0.327 & 0.001 & 0.132 & 0.789 & 0.530 \\
\hline & $1 \mathrm{~L}: \mathrm{BE}_{\mathrm{h}} \leftrightarrow \mathrm{BE}_{\mathrm{s}}$ & 0.123 & 0.626 & 0.046 & 0.092 & 0.420 & 0.012 & 0.480 & 0.430 \\
\hline & $2 \mathrm{~L}: \mathrm{BE}_{\mathrm{h}} \leftrightarrow \mathrm{BE}_{\mathrm{s}}$ & 0.421 & 0.818 & 0.171 & 0.403 & 0.265 & 0.001 & 0.003 & 0.523 \\
\hline
\end{tabular}

the maximal moment in the back, $\mathrm{M}_{\mathrm{b}, \mathrm{max}}$, is two to three times smaller during BE [maximal back moment $=2.75-$ $2.81 \mathrm{Nm} / \mathrm{kg}$ with 25\% extra barbell load for deadlifts and goodmornings; 27].

\section{Hip}

\section{Kinematics}

Because of different exercise specifications, $\operatorname{RoM}_{h}$ was expected to be higher for $\mathrm{BE}_{\mathrm{h}}$ compared to $\mathrm{BE}_{\mathrm{s}}$. This assumption was confirmed by the results (Fig. 2b, Tables 2 and 3). Larivière and co-workers [7] achieved a RoM $\mathrm{M}_{\mathrm{h}}$ of $13^{\circ}$, which was in accordance with this study's $\mathrm{BE}_{\mathrm{s}}$ values. The smaller $\operatorname{RoM}_{h}$ for $1 \mathrm{~L}$ compared to $2 \mathrm{~L}$ (Fig. 2b) could be explained by the inability of the participants to fully extend their hip in the starting position of $1 \mathrm{~L}$ executions due to a lack of stabilising capacity.

\section{Kinetics}

Similar to the kinetic results in the lower back, the maximal moment in the hip, $M_{h, \max }$, was slightly higher for $\mathrm{BE}_{\mathrm{h}}$ compared to $\mathrm{BE}_{\mathrm{s}}$ (Fig. 2b, Tables 2 and 3), which presumably resulted in a higher training effect for the dorsal hip muscles during $\mathrm{BE}_{\mathrm{h}}$. Additionally, a significantly higher $M_{h, \max }$ and, thus, probably a better training effect were achieved for $1 \mathrm{~L}$ compared to $2 \mathrm{~L}$ for both types of BE (Fig. 2b, Tables 2 and 3).

Comparing to other strength exercises, $M_{h, \max }$ during $2 \mathrm{~L} \mathrm{BE}$ was similar to squats without any extra load [27, 28] and was approximately half for $2 \mathrm{~L}$ and two thirds for $1 \mathrm{~L}$ of the load reached by deadlifts and goodmornings with 25\% BW extra barbell load [29]. The latter is quite astonishing, considering that the $\mathrm{BE}$ were performed without any extra load. For comparison with this study's results, the maximal hip moment for $45^{\circ} \mathrm{BE}$ calculated by Contreras and coworkers [6] was normalised with BW (5.43 Nm/kg). Because they used an external weight of approximately $50 \% \mathrm{BW}$, it is reasonable that their value is approximately five times larger than what the present study measured for $\mathrm{M}_{\mathrm{h} \text {,max }}$.

\section{Knee}

\section{Kinematics}

Unsurprisingly, a small $\operatorname{RoM}_{\mathrm{k}}$ was expected and confirmed in this study because the $\mathrm{BE}$ were performed with straight legs (Fig. 2a, Tables 2 and 3). Similar $\mathrm{RoM}_{\mathrm{k}}$ values were obtained for the straight leg exercise goodmornings [29]. The $\mathrm{RoM}_{k}$ is significantly higher for $\mathrm{BE}_{\mathrm{h}}$, and the starting positions differ between $\mathrm{BE}_{\mathrm{h}}$ and $\mathrm{BE}_{\mathrm{s}}$ (Fig. 2a, Tables 2 and 3). To increase the $R_{h} M_{h}$ for $B_{h}$, participants might have tilted their pelvis forward, which could have promoted knee extension and thus increased the RoM $\mathrm{M}_{\mathrm{k}}$. However, compared to other strength exercises, the $\operatorname{RoM}_{k}$ is still extremely small. In the starting position of $1 \mathrm{~L}$, the knee might have been more extended than in the starting position of $2 \mathrm{~L}$ due to stabilising reasons and higher moments (Fig. 2a, Tables 2 and 3).

\section{Kinetics}

For the knee joint not being directly involved in the movement, high $\mathrm{M}_{\mathrm{k} \text {,max }}$ were obtained, especially for $\mathrm{BE}_{\mathrm{h}}$ and $1 \mathrm{~L}$ executions. It is important to note that $\mathrm{M}_{\mathrm{k}, \max }$ is an extension moment and is thus supporting the isometric contraction of the hamstrings and providing a training effect for these muscles. In addition to the positive effect on the hamstrings, the extension moment might exert forces on the passive structures in the knee, which must be considered in patients with current or past knee injuries. As far as we know, no one has ever looked at the kinematics and kinetics in the knee during $\mathrm{BE}$ although this exercise might shift the quadriceps/hamstring ratio towards hamstring as part of an Anterior cruciate ligament (ACL) prevention program. The knee extension moments obtained for goodmornings were slightly higher, probably due to the extra barbell load of $25 \%$ BW [29].

\section{Muscular activity}

Because BE are a dynamic exercise, the EMG results must be treated and interpreted with caution due to 
skin artefacts. This caution is especially important for the comparison between $\mathrm{BE}_{\mathrm{h}}$ and $\mathrm{BE}_{\mathrm{s}}$, which are different movements.

In general, all muscles were more active during the concentric phase than during the eccentric phase (Tables 4 and 5). For the concentric phase, the activity levels for gluteal muscles and hamstrings agree with the literature [1]. The activity level for lumbar and thoracic dorsal back muscles are considerably lower (lumbar: 39-56\% MVC, thoracic: 43\% MVC; [1]). For gluteal muscles and hamstrings, no significant differences between $\mathrm{BE}_{\mathrm{h}}$ and $\mathrm{BE}_{\mathrm{s}}$ were found, which agrees with the results of Mayer and co-workers [8], who did not find any influence of lumbar posture on these muscles. Moreover, they also observed that an accentuated lumbar lordosis increased the activity of the lumbar extensors, whereas the present study found, for ErecLum, no significant differences between $\mathrm{BE}_{\mathrm{h}}$ and $\mathrm{BE}_{\mathrm{s}}$. However, due to the different MVC measurement settings, electrode placements, starting positions and exercise executions, a direct comparison between different studies is difficult. The only study looking at the muscle activities in the eccentric phase of the BE exercise was a study by De Ridder and co-workers [13], who considered $\mathrm{BE}$ performed in a horizontal position and with an extra load of $60 \% 1 \mathrm{RM}$. Due to the extra load, a comparison of the values between their study and the present study is not reasonable.

As expected, the ventral trunk muscles were almost inactive (2-5\% MVC), which agrees with the results of Callaghan and co-workers [11]. The high standard deviations (see Table 4) suggest that some participants needed to activate those muscles more than others to stabilise the trunk.

\section{Comparison of types $\mathrm{BE}_{\mathrm{h}}$ and $\mathrm{BE}_{\mathrm{s}}$}

Apart from the obvious differences in $\operatorname{RoM}_{\mathrm{mub}}, \mathrm{RoM}_{\mathrm{lmb}}$ and $\mathrm{RoM}_{\mathrm{h}}$, there were other relevant differences between $B E_{h}$ and $B_{s} . B_{h}$ showed higher external moments in hip, knee and lower back with higher or similar RoMs (Fig. 2a-c, Tables 2 and 3). This finding suggests a higher training effect for $\mathrm{BE}_{\mathrm{h}}$ for dorsal back and hip muscles and for hamstrings. However, the above-mentioned opposed movement in the spine for $\mathrm{BE}_{\mathrm{h}}$ must be considered.

\section{Comparison of versions $1 \mathrm{~L}$ and $\mathbf{2 L}$}

The $1 \mathrm{~L}$ version showed higher external moments in the hip and knee with smaller or similar RoMs (Fig. 2a-c, Tables 2 and 3). Because strength training requires high moments with high RoMs, we are unsure whether $1 \mathrm{~L}$ provides a greater training effect for the dorsal hip muscles and hamstrings than $2 \mathrm{~L}$. These results suggest that the version should be chosen according to the specific requirements, i.e., whether high RoM or high external moments are desired.

\section{Conclusions}

In strength training, high moments with wide RoMs in the trained joint are desired in order to minimise the load on other parts of the body. To strengthen the hip and lower back, $\mathrm{BE}_{\mathrm{h}}$ seem to be more efficient due to higher moments with higher or similar RoMs in the hip and lower back. According to Callaghan and co-workers [11], disk deformation, ligament and spinal loading can be reduced if $\mathrm{BE}$ exercises are performed with neutral lordosis. Therefore, $\mathrm{BE}_{\mathrm{h}}$ are not only more efficient for training but also healthier. However, athletes and patients must be aware of the opposed movement in the lumbar and thoracic spine when performing $\mathrm{BE}_{\mathrm{h}}$.

Due to the extension moment in the knee and the flexion moment in the hip, $1 \mathrm{~L} \mathrm{BE}$ in particular, provide an effective training to strengthen the dorsal part of the limb in a specific RoM, especially the hamstrings and glutes. However, patients with knee deficits must be aware of the high external moments in the knee in $1 \mathrm{~L}$ BE. In the future, kinetic and kinematic analysis combined with subject specific musculoskeletal modelling allow to quantify the individual loading conditions during strength training exercises.

\begin{abstract}
Abbreviations
$\left(M_{k, m a x}\right)$ : Maximal joint moments of the knee $[\mathrm{Nm} / \mathrm{kg}] ; 1 \mathrm{~L}$ : One leg; $2 \mathrm{~L}$ : Two legs; Abdo: M. Rectus abdominis; ACL: Anterior cruciate ligament; BE: Back extension; $\mathrm{B} E_{h}$ : Back extension dynamic hip; $\mathrm{BE}_{\mathrm{s}}$ : Back extension dynamic spine; BW: Body weight; $\mathrm{C}$ : Thoracic curvature [1/m]; $\mathrm{C}_{1}$ : Lumbar curvature [1/ $\mathrm{m}] ; \mathrm{C}_{1, \mathrm{r} p}$ : Lumbar curvature at the reversal point $[1 / \mathrm{m}] ; \mathrm{C}_{1, s}$ : Lumbar curvature at the start $[1 / \mathrm{m}] ; C_{t, r p}$ : Thoracic curvature at the reversal points $[1 / \mathrm{m}]$; $C_{t, s}:$ Thoracic curvature at the start [1/m]; EMG: Electromyography; ErecLum: Lumbar part of $M$. erector spinae; ErecThor: Thoracic part of $M$. erector spinae; FFT: Fast-Fourier-Transformation; GlutMax: M. Gluteus maximus; GlutMed: M. Gluteus medius; HamLat: Lateral hamstrings; HamMed: Medial hamstrings; L: Leg; L4/L5: Between lumbar vertebra 4 and 5; $\mathrm{M}_{\mathrm{b} \text {,max: Maximal }}$ joint moments of the back at $L 4 / L 5[\mathrm{Nm} / \mathrm{kg}] ; M_{\mathrm{h} \text { max: }}$ Maximal joint moments of the hip [Nm/kg]; MVC: Maximum voluntary contraction; Obli: M. Obliquus externus abdominis; RoM: Range of motion [0]; RoM : RoM in the hip [0]; RoMk: RoM in the knee ["]; RoMImb: RoM lower to middle back ["];

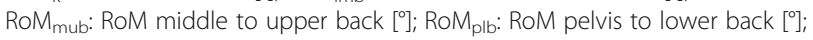
RoMs: Ranges of motion [ ["]
\end{abstract}

\section{Acknowledgements}

We kindly thank Janine Weigand for the construction of the bench and Edeny Baaklini, Michele Mazzariello and Anna Kratschmar for measurement support.

\section{Funding}

No funding from third parties was contributed.

\section{Availability of data and materials \\ The dataset generated and analysed during the current study are available from the corresponding author on reasonable request. Raw data and analysed results are stored for the next ten years at the laboratory for movement biomechanics, ETH Zurich, Switzerland.}

\section{Authors' contributions}

$\mathrm{FS}, \mathrm{RH}$ and $\mathrm{NH}$ acquired the data and undertook the data analyses including the preparation of the tables and figs. FS and NS performed the statistical analysis and helped drafting the manuscript. BT helped in both interpreting the data and drafting the manuscript. FS and SL conceptualised and designed the study, supervised the data analyses and interpretation and helped draft the manuscript. All authors read and approved the final manuscript. 


\section{Competing interests}

The authors declare that they have no competing interests.

\section{Consent for publication}

Written consent was obtained for the publication of fig. 1 from the participant shown

\section{Ethics approval and consent to participate}

This study was approved by the ethics committee of ETH Zurich, Switzerland (EK 2014-N-31). All participants provided written agreement to be part of this study and one participant to publish this figure.

\section{Publisher's Note}

Springer Nature remains neutral with regard to jurisdictional claims in published maps and institutional affiliations.

Received: 2 February 2017 Accepted: 6 April 2017

Published online: 24 April 2017

\section{References}

1. Da Silva RA, Larivière C, Arsenault AB, Nadeau S, Plamondon A. Effect of pelvic stabilization and hip position on trunk extensor activity during back extension exercises on a roman chair. J Rehabil Med. 2009:41:136-42.

2. Müller R. Fitness Centers: Injuries and Discomforts During Training. Federal Institute for Injury Prevention. Bern: BFU; 1999.

3. Biering-Sorensen F. Physical measurements as risk indicators for Low-back trouble over a One-year period. Spine. 1984;9(2):106-19.

4. Hansen JW. Postoperative management in lumbar disc protrusions. I. Indications, method and results. II. Follow-up on a trained and an untrained group of patients. Acta Orthop Scand. 1964;35 Suppl 71:3-47.

5. Champagne A, Descarreaux M, Lafond D. Back and Hip extensor muscles fatigue in healthy subjects: task-dependency effect of Two variants of the sorensen test. Eur Spine J. 2008;17(12):1721-6.

6. Contreras BM, Cronin JB, Schoenfeld BJ, Nates RJ, Tiryaki Sonmez G. Are All Hip extension exercises created equal? Strength Cond J. 2013;35(2):17-22.

7. Larivière C, Da Silva RA, Arsenault AB, Nadeau S, Plamondon A, Vadeboncoeur R. Specificity of a back muscle roman chair exercise in healthy and back pain subjects. Med Sci Sports Exerc. 2011:43(1):157-64.

8. Mayer JM, Verna JL, Manini TM, Mooney V, Graves JE. Electromyographic activity of the trunk extensor muscles: effect of varying Hip position and lumbar posture during roman chair exercise. Arch Phys Med Rehabil. 2002; 83(11):1543-6.

9. Mayer JM, Graves JE, Robertson VL, Pierra EA, Verna JL, Ploutz-Snyder LL Electromyographic activity of the lumbar extensor muscles: effect of angle and hand position during roman chair exercise. Arch Phys Med Rehabil. 1999:80:751-5

10. Mannion AF, Dolan P. The effects of muscle length and force output on the EMG power spectrum of the erector spinae. J Electromyogr Kinesiol. 1996;6(3):159-68.

11. Callaghan JP LGJ, McGill SM. The relationship between lumbar spine load and muscle activity during extensor exercises. Phys Ther. 1998;78:8-18.

12. Clark BC, Manini TM, Mayer JM, Ploutz-Snyder LL, Graves JE. Electromyographic activity of the lumbar and Hip extensors during dynamic trunk extension exercise. Arch Phys Med Rehabil. 2002;83:1547-52.

13. De Ridder EM, Van Oosterwijck JO, Vleeming A, Vanderstraeten GG, Danneels LA. Posterior muscle chain activity during various extension exercises: an observational study. BMC Musculoskelet Disord. 2013;14(1):204.

14. Haff GG, Triplett NT. Essentials of Strength Training and Conditioning. 4th ed. Human kinetics 2015.

15. List R, Gulay T, Stoop M, Lorenzetti S. Kinematics of the trunk and the lower extremities during restricted and unrestricted squats. J Strength Cond Res. 2013;27(6):1529-38.

16. Dettwyler M, Stacoff A, Stüssi E. Static in situ calibration of statically overdetermined ground reaction force measurement platforms. In: Milburn P, Wilson B, Yanai T, editors. XIXth international congress of biomechanics. Dunedin, New Zealand: University of Otago; 2003. p. 88.

17. De Luca CJ. Use of the surface EMG signal for performance evaluation of back muscles. Muscle Nerve. 1993;16(2):210-6.

18. Vera-Garcia FJ, Moreside JM, MCGill SM. MVC techniques to normalize trunk muscle EMG in healthy women. J Electromyogr Kinesiol. 2010;20(1):10-6.
19. Nissan M, Gilad I. Dimensions of human lumbar vertebrae in the sagittal plane. J Biomech. 1986:19:753-8.

20. Zatsiorsky VM. Kinetics of human motion: human kinetics. 2002.

21. Hof $L$. An explicit expression for the moment in multibody systems. J Biomech. 1992;25(10):1209-11.

22. Durkin $J$, Dowling J. Analysis of body segment parameter differences between four human populations and the estimation errors of four popular mathematical models. J Biomech Eng. 2003;125(4):515-22.

23. Gander W, Hrebicek J. Solving problems in scientific computing using Maple and Matlab ${ }^{\circledR}$. Berlin: Springer Science \& Business Media; 2011.

24. Woltring HJ. 3-D attitude representation of human joints: a standardization proposal. J Biomech. 1994;27(12):1399-414.

25. Konrad P. The ABC of EMG: A Practical Introduction to Kinesiological Electromyography. Scottsdale, AZ; 2006

26. Plamondon A, Serresse O, Boyd K, Ladouceur D, Desjardins P. Estimated moments at L5/S1 level and muscular activation of back extensors for Six prone back extension exercises in healthy individuals. Scand J Med Sci Sports. 2002;12:81-9.

27. Farris DJ, Lichtwark GA, Brown NAT, Cresswell AG. Deconstructing the power resistance relationship for squats: A joint-level analysis. Scand J Med Sci Sports. 2016;26:774-81. doi:10.1111/sms.12508.

28. Lorenzetti S, Gülay T, Stoop M, List R, Gerber H, Schellenberg F, Stüssi E. Comparison of the angles and corresponding moments in the knee and Hip during restricted and unrestricted squats. J Strength Cond Res. 2012; 26(10):2829-36.

29. Schellenberg F, Lindorfer J, List R, Taylor WR, Lorenzetti S. Kinetic and kinematic differences between deadlifts and goodmornings. BMC Sports Sci Med Rehabil. 2013:5(1):27.

\section{Submit your next manuscript to BioMed Central and we will help you at every step:}

- We accept pre-submission inquiries

- Our selector tool helps you to find the most relevant journal

- We provide round the clock customer support

- Convenient online submission

- Thorough peer review

- Inclusion in PubMed and all major indexing services

- Maximum visibility for your research

Submit your manuscript at www.biomedcentral.com/submit 